\title{
Effect of exposure frequencies of pear juice on tooth whitening
}

\author{
Gobalakrishna Munusamy*, Endang Sukartini*, Ayu Trisna Hayati* \\ ${ }^{*}$ Department of Conservative Dentistry Faculty Of Dentistry Universitas Padjadjaran
}

\begin{abstract}
Introduction: Tooth whitening (Bleaching) is a method to restore discoloured teeth to the original tooth colour with a chemical process. The materials used in the bleaching process are hydrogen peroxide, sodium perborates and carbamide peroxide. Pear fruit consists of hydrogen peroxide which is potentially an oxidizing compound that produces free radicals that react with unsaturated bonding teeth staining substances. This study aims to analyzed tooth whitening effect of exposure of pear juice with different frequencies. Methods: The type of research was true in vitro experiment where samples of 32 maxillary premolar teeth had cut the root to CEJ. The specimens divided into four groups. The first group was soaked in pear juice two times, the second group three times, a third group four times, and the fourth was the control group using only mineral water. Tooth colour was measure using a Spectrophometer, conducted before and after individual soaking. Results: The research result is tested with ANOVA and Newman- Keuls Range Test showed a significant difference of tooth whitening degree between the frequency exposure pear juice after 2 times soaking, 3 times soaking and 4 times soaking. Conclusion: There are difference degree of whitening from the difference frequency exposure of pear juice and Pear juice exposure of 4 times gives higher whitening effect compared to frequency of 3 times, 2 times and control group which is soaked in water.
\end{abstract}

Keywords: Bleaching, the frequency of exposure, pear juice

\section{INTRODUCTION}

Changes in tooth color especially at the anterior region can be an esthetic problem that will give a psychological impact to the patient to seek treatment. Tooth color changes can be divided into two groups which are extrinsic and intrinsic tooth color changes. Extrinsic tooth discoloration is caused by external factors such as poor oral hygiene, stains from tobacco, tea, coffee and cola. While intrinsic tooth discoloration is caused by internal factors such as tetracycline consumption, pulp necrosis, amalgam fillings, disease such as sickle cell anemia, thalassemia and impaired growth and tooth development). ${ }^{1}$

Esthetic dentistry is rapidly growing in efforts to address the problem of tooth discoloration. There are various ways that can be done either with restorative procedures such as crown layer (veneer) or with the bleaching process. Bleaching is one of the ways to restore tooth color that have undergone discoloration by means of a chemical 
process. The bleaching treatment uses hydrogen peroxide as the active chemical. There are several advantages in this bleaching technique which include better aesthetics, require less time and treatment techniques that are cheaper compared to making an artificial crown. The disadvantages of bleaching technique include the use of active chemicals which produce free radicals that are harmful to the gingival structure, fractures if the crown and possibly external resorption. ${ }^{1}$

Most fruits naturally contain hydrogen peroxide. According to research done by Thomas Brennan and Frenkel (1977), pear (Pyrus communis) contains hydrogen peroxide which serves to initiate ripening of the fruit itself. ${ }^{2}$ Previous research by Song and Palmer (2008), also found hydrogen peroxide to be present in fruits and vegetables for metabolic synthesis. ${ }^{3}$ Hydrogen peroxide, through reactive free radicals reaction can destroy the conjugation bonding in the dye molecules of the stain so that the molecules become much less pigmented and therefore give the effect of whitening. ${ }^{3}$ This study aims to analyzed tooth whitening effect of exposure of pear juice with different frequencies

\section{METHODS}

The research is a true experimental in vitro. Population sample is maxillary first premolar teeth collected from Klinik Padjadjaran from the period of September-November 2010. Collected teeth were preferably those that were extracted for orthodontic purpose. Inclusion criteria for the research are Tooth without caries and restoration, Teeth with completed root formation and tooth extracted for orthodontic needs. Thirty two premolar teeth with crown which fulfilled the population criteria, soaked in pear juice and artificial saliva. Research tools are Spectrophotometer, Incubator, Test tube for soaking tooth, Writing materials, Polish brush, Measurement glass, Stop watch and High Speed contra angle.

Research material are Thirty two premolar teeth that are kept in physiologic solution of $\mathrm{NaCl}$ 0.9\%, Pear fruit juice, Nail varnish and Artificial saliva type AFNOR. Data collected from measurement result from Spectrophotometer continued to analyzed statistically using ANOVA and Multiple Comparison Newman-Keuls test with the help of computer program (Statistical Package for Social Science) version13.

\section{RESULTS}

Research mainly aimed to evaluate and measure tooth whitening effect in tooth soaked in pear juice with different frequency exposures. Besides that, research results helped to determine the frequency required to provide maximum whitening effect. Research sample consisted of 32 teeth divided to 4 groups of action whereby, there were teeth with soaking process in pear juice for 2 times (group I), teeth with soaking process in pear juice for 3 times (group II), teeth with soaking process in pear juice for 4 times (group III) and teeth group with soaking process in mineral water (group IV). Each group contains 8 unit samples and the soaking process done for 7 days. Measurement of tooth colour before and after soaking done in Laboratory of Chemical Physic Textile Bandung. Data measurement of tooth colour before and after soaking could be seen Appendix 4 Result from the research were done presented in statistical data with mean differences in whitening degree of the tooth specimen before and after presented in Table 1.

From the Table 1. the mean value that was recorded from the degree of whitening effect from Group I was 0.07, Group II was 1.19, Group III was 1.50 and Group IV was -0.13. Different changes of tooth colour degree for the three groups presented in Figure 1.

Figure 1. shows the mean value of different whitening degree between treatment groups. The value of mean difference shows that degree of whitening specimen tooth group IV was more less compared to other three groups and group III showed a big difference of mean value. This proved that group III showed highest difference of whitening and group IV showed the least difference of whitening. Statistical test was done to know if there were difference between exposure frequency pear juice and the whitening level effects of the tooth specimens. The result from the ANOVA was presented below in Table 2 .

Anova test has parameter significance 
Table 1. Degree of tooth whitening before and after soaking

\begin{tabular}{|c|c|c|c|c|}
\hline Group & Sample number & Degree of tooth whitening & Mean value & Standard division \\
\hline \multirow[t]{8}{*}{ Group I } & 1 & 0.06 & 0.07 & 0.54 \\
\hline & 2 & 0.21 & & \\
\hline & 3 & 0.18 & & \\
\hline & 4 & 0.05 & & \\
\hline & 5 & 0.25 & & \\
\hline & 6 & 0.1 & & \\
\hline & 7 & 0.86 & & \\
\hline & 8 & -1.12 & & \\
\hline \multirow[t]{8}{*}{ Group II } & 9 & -2.95 & 1.19 & 1.19 \\
\hline & 10 & 2.68 & & \\
\hline & 11 & 0.59 & & \\
\hline & 12 & 1.13 & & \\
\hline & 13 & 1.14 & & \\
\hline & 14 & 2.32 & & \\
\hline & 15 & 2.23 & & \\
\hline & 16 & 2.34 & & \\
\hline \multirow[t]{8}{*}{ Group III } & 17 & 1.32 & 1.50 & 0.60 \\
\hline & 18 & 1.01 & & \\
\hline & 19 & 0.72 & & \\
\hline & 20 & 2.12 & & \\
\hline & 21 & 0.79 & & \\
\hline & 22 & 2.12 & & \\
\hline & 23 & 1.91 & & \\
\hline & 24 & 2.02 & & \\
\hline \multirow[t]{8}{*}{ Group IV } & 25 & -0.46 & -0.13 & 0.25 \\
\hline & 26 & 0.01 & & \\
\hline & 27 & -0.25 & & \\
\hline & 28 & -0.56 & & \\
\hline & 29 & -0.02 & & \\
\hline & 30 & 0.02 & & \\
\hline & 31 & 0.03 & & \\
\hline & 32 & 0.12 & & \\
\hline
\end{tabular}

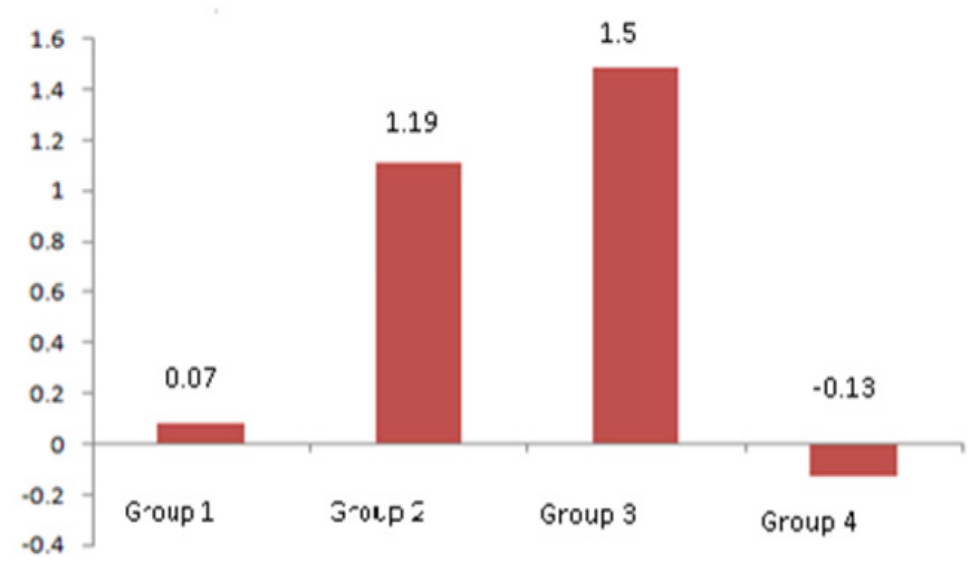

Figure 1. Mean difference in degree of whitening of tooth specimens before and after soaking (explaination $a=0.05$ ) 
Table 2 ANOVA Test (Explaination $\alpha=0.05$ )

\begin{tabular}{cccccc}
\hline Description & Sum of Squares & Df & Mean Square & $\mathrm{F}$ & Siq \\
\hline Between Groups & 15.19 & 3 & 5.06 & 4.28 & .013 \\
Within Groups & 33.09 & 28 & 1.18 & & \\
\hline Total & 48.28 & 31 & & \\
\hline
\end{tabular}

Table 3. Multiple comparison newman- keuls test

\begin{tabular}{lcc}
\hline \multicolumn{1}{c}{ Action } & \multicolumn{2}{c}{ Value multiple comparison } \\
\hline Group I vs GrouplI & 0.64 & Not significant \\
Group I vs Group III & 0.14 & Significant \\
Group I vs Group IV & 0.699 & Not significant \\
Group II vs Group III & 0.489 & Not significant \\
Group II vs Group IV & 0.028 & Significant \\
Group III vs Group IV & 0.05 & Significant \\
\hline
\end{tabular}

$\leq 0,05$ it will reject Ho. The result of ANOVA in the research has a significant value of 0.013 which is less than 0.05 which is the significant parameter to reject the $\mathrm{Ho}$, therefore accepting $\mathrm{H} 1$ which states there are whitening effect present when the teeth are soaked in the pear juice.

Statistical analysis Multiple Comparison Newman- Keuls test done to determine the different significance between treatment group. The result of the test $\mathrm{cn}$ be presented in Table 3. There were no significant differences between Group 1 with Group II, Group I and Group III. There were significant differences when Group I was compared with Group III, Group II with Group IV and Group III with Group IV.

\section{DISCUSSION}

Bleaching is a method that can return normal tooth color due to discoloration by intrinsic and extrinsic factors by changing the stain color to be brighter using a strong oxidation substance.

In the research done by Song and Palmer (2008) and Brennan and Frenkel (1977), it was said that hydrogen peroxide is one of the product produced by fruits and vegetable in metabolism process. ${ }^{3,2}$ This research used the cells of pear fruit where hydrogen peroxide was responsible in the oxidation process and initiates the process of fruit maturation. The increase of hydrogen peroxide in the fruit tissues will increase the maturation process of the fruit. Formation of hydrogen peroxide in the pear fruit comes from the isolated mitochondria and chloroplast. In $100 \mathrm{mg}$ of the pear fruit tissue, there is an estimation of 2 gram of hydrogen peroxide during initiation of maturation and will increase along with the maturation of fruit. This hydrogen peroxide can be used as a tooth bleaching agent through reactive free radical. Free radical is pure oxygen that can damage conjugated chains on stain colour molecule that has attached on the enamel and dentine surface. With the conjugated chain broken, the colour molecule becomes smaller and less pigmented. This causes teeth to be whiter. ${ }^{2-5}$

Statistical analysis with ANOVA test shows significant difference of tooth whitening degree between the group. Multiple Comparison NewmanKeuls Test shows there are significant difference between Group I with soaking in pear juice for 2 times a day towards Group III with soaking in pear juice for 4 times a day. Group II with soaking I $\mathrm{n}$ pear juice for 3 times a day shows significant difference towards Group IV which is soaked with mineral water. Group III with soaking in pear juice for 4 times a day shows significant difference towards Group IV with soaking in mineral water for 4 times a day. This research shows similar result with the research done by Adiyanto on 2009 by in-vitro, to see the whitening effect on the enamel of the teeth from the exposure of pear juice in bleaching process. ${ }^{4}$ Previous research done by Adiyanto on 2009 to see the whitening effect of the teeth from the exposure of pear juice in bleaching process showed no significant difference between three sample groups. This 
research was an experimental in vitro study using pre-post test controlled groups, each group contained 5 teeth. The teeth as samples were soaked in pear juice (Pyrus communis) for 24, 48 and 72 hours respectively. The colour of the teeth were measured with spectrophotometer before and after treatment. The difference in the result obtained from Adiyanto's research and this research can be due to influence of svereal factors such as the concentration of pear juice, quantity of the sample and age of the tooth used as samples.

The result occurred due to high content of hydrogen peroxide present in pear fruit. This statement is supported by Roberson in the year 2006, whereby the effectiveness of bleaching treatment is connected to bleaching material used. The higher the concentration of whitening material is reacting with the tooth surface, the whiter the tooth colour will be due to large number of free radical reacting with coloured ions in the enamel forming bright coloured molecules. ${ }^{6}$

The research showed that the whitening degree of each tooh was different. This might be due to few factors such as the age of the tooth, damage on the enamel, tooth has gone through flourisis. As the older the age of a tooth there seem to be higher amount of the secondary dentine thar will effect the translucency of the enamel colour. Besides that,extraction procedure usually cause damage to enamel that affects the absorption of solour due to the exposed of tubular dentine. The effect of bleaching on flourisis tooth becomes ineffective because the enamel $\mathrm{OH}$ - grup of hydroxyapatite is replaced by a chain of $\mathrm{F}$ so that the effect on the tooth bleaching has become ineffective because the bond flourapatite is hard to break. ${ }^{7}$

\section{CONCLUSION}

There are difference degree of whitening from the difference frequency exposure of pear juice and Pear juice exposure of 4 times gives higher whitening effect compared to frequency of 3 times, 2 times and control group which is soaked in water.

\section{REFERENCES}

1. Walton, Torabinejad. Prinsip dan praktik ilmu endodonsi. Jakarta: EGC. 2002. p. 1-40.

2. Brennan T, Frenkel C. Involvement of Hydrogen Peroxide in The Regulation of Senescence in Pear. 1977. p. 59. Available from: http:// www.plantphysiol.org/cgi/conten/abstract.

3. Song S, PalmerL. Amodified chemiluminescence method forhydrogen peroxide determination in apple fruit tissues. Available from:http// www.sciencedirect.com/science [Cited 16 Jun 2011]. 2008.

4. Adiyanto 10. Pengaruh lama perendaman gigi dengan jus buah pir (Pyrus communis) terhadap Perubahan Warna Gigi pada Proses Pemutihan Gigi Secara In Vitro. Semarang: Universitas Diponegoro. 2009. p. 8-13.

5. Reksodiputro S, Rezki. Efek jus buah stroberi terhadap pemutihan kembali permukaan email gigi yang berubah warna karena kopi. Jakarta: Universitas Indonesia. 2004. p. 1-29.

6. Roberson TM. Art and science of operative dentistry. Philadelphia: Mosby Elsevier. 2006. p. 18-23.

7. Osborn JW, Ten Cate AR. Advanced dental history, $4^{\text {th }}$ ed. London: Wright. 1983. p. 2528. 